\title{
The Effects of Angiotensin II and Indomethacin on the Pulmonary Arterial Prostaglandin E Levels and Pulmonary Circulation in Dogs
}

\author{
Takayuki Ito, M.D. and Kouichi Ogawa, M.D.
}

\begin{abstract}
SUMmary
We studied whether pulmonary arterial levels of plasma prostaglandin $\mathrm{E}$ rose following pressor effects of angiotensin II in the intact dogs. Furthermore, the modulation by indomethacin of the effect of angiotensin II, $\mathrm{PGF}_{2^{\alpha}}$, and $\mathrm{PGE}_{1}$ on pulmonary circulation was evaluated. Pulmonary arterial plasma PGE levels rose significantly from $0.52 \pm$ 0.10 (SE) $\mathrm{ng} / \mathrm{ml}$ to $0.85 \pm 0.07$ by the infusion of angiotensin II. This increase was not observed when indomethacin was given. The rise in pulmonary arterial pressure and total pulmonary resistance by angiotensin II was augmented significantly with pretreatment of indomethacin. These results showed that there was an augmentation of the pulmonary vasoconstrictor action of angiotensin II as indomethacin blocked an increase of pulmonary arterial PGE level. Thus, it was suggested that prostaglandins (especially $P G E$ ) modulated the pulnomary vasoconstrictor effects of angiotensin II.
\end{abstract}

\section{Additional Indexing Words :}

Radioimmunoassay Prostaglandin $\mathrm{E}_{1}$ Prostaglandin $\mathrm{F}_{2^{\alpha}} \quad$ Total pulmonary resistance Pulmonary arterial blood pressure Cardiac output Max RV dp/dt

7 HE prostaglandins are a group of unsaturated hydroxy-carboxylic acid 1 that are widely distributed in normal tissues and have diverse biological activity. The study on the cardiovascular actions of these compounds in man and experimental animals showed that prostaglandins of $\mathrm{E}$ - and A-type were potent vasodilators, but prostaglandin $\mathbf{F}_{2 a}\left(\mathbf{P G F}_{2 a}\right)$ was a weak vasoconstrictor agent in most peripheral vascular beds. ${ }^{11,2)}$ In the pulmonary vascular bed, $\mathrm{PGF}_{2 \alpha}$ is a potent vasoconstrictor, whereas $\mathrm{PGE}_{1}$ and $\mathrm{PGA}_{1}$ are moderately active vasodilator agents. ${ }^{3,4)}$ In addition to their direct effect on vascular smooth muscle, the prostaglandins modulate effects of pressor hormones in a number of vascular beds. ${ }^{51-11}$ It has been reported that angiotensin II, a vasoconstrictor agent, stimulates releases of prostaglandins from the kidney, ${ }^{51,6)}$

From the Second Department of Internal Medicine, Nagoya University School of Medicine, 65

Tsurumacho, Showa-ku, Nagoya 466, Japan.

Received for publication July 3, 1978.

Manuscript revised September 12, 1978 
cultured vascular endothelium" and vascular wall.91,10) Although there are reports showed that angiotensin II strongly stimulated a release and synthesis of prostaglandin, there is no report showing the effect of angiotensin II on pulmonary arterial blood levels of prostaglandin $\mathrm{E}$.

We studied whether pulmonary arterial levels of plasma prostaglandin $E$ rose following pressor effects of angiotensin II in the intact dogs. Furthermore, the modulation by indomethacin, an inhibitor of prostaglandin synthesis, of the effects of angiotensin II, $\mathbf{P G F}_{\mathbf{2}_{\alpha}}$ and $\mathrm{PGE}_{\mathbf{1}}$ on pulmonary circulation was evaluated in the intact dogs.

\section{Materials and Methods}

Exprimental procedure:

Forty-eight mongrel dogs of either sex weighing $7.5-19 \mathrm{Kg}$ were used for this experiment and anesthetized with pentobarbital sodium. A 7F catheter was positioned in the peripheral pulmonary arterial branch of the right lower pulmonary lobe under fluoroscopic guidance and pulmonary arterial blood pressure was recorded on a polygraph connected to a transducer. Aortic and right ventricular pressures and $\max \mathrm{dp} / \mathrm{dt}$ of right ventricle (RV) were measured continuously with transducers connected to catheters placed both in the aorta and in the right ventricle simultaneously. Cardiac output was measured by the thermal dilution method with a $5 \mathrm{~F}$ thermodilution catheter placed in the pulmonary artery in 14 dogs using the KIMRY Model 3500 cardiac output computer. Total pulmonary resistance (TPR) was obtained by the following formula:

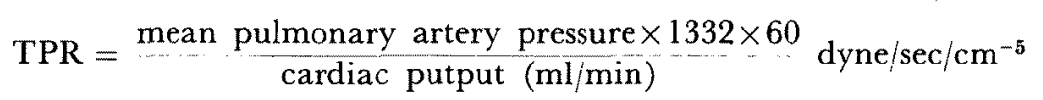

All infusions were made through a catheter in the right ventricle. The angictensin II, $\mathrm{PGF}_{2 \alpha}$, and $\mathrm{PGE}_{1}$ freshly solved daily in saline solution were infused for $10 \mathrm{~min}$ into the right ventricle; angiotensin II at a rate of $0.5 \mu \mathrm{g} / \mathrm{Kg} / \mathrm{min}, \mathrm{PGF}_{2 a}$, and $\mathrm{PGE}_{\mathbf{1}}$ at a rate of $1.0 \mu \mathrm{g} / \mathrm{Kg} / \mathrm{min}$ with an infusion pump. Indomethacin $(5 \mathrm{mg} /$ $\mathrm{Kg}$ ) was mixed with equimolar amounts of sodium carbonate, and the resulting solution was diluted in $20 \mathrm{ml}$ physiologic saline and injected into the right ventricle $20 \mathrm{~min}$ before the infusion of these substances. The responses of pulmonary arterial, aortic, and right ventricular pressures, cardiac output, total pulmonary resistance, and $\max \mathrm{dp} / \mathrm{dt}$ of $\mathrm{RV}$ in dogs treated with indomethacin following intra-ventricular infusion of these substances were compared with those in control dogs. Two $\mathrm{ml}$ of peripheral pulmonary blood sample was obtained before and after the continuous infusion of $0.5 \mu \mathrm{g} / \mathrm{Kg} / \mathrm{min}$ of angiotensin II for $10 \mathrm{~min}$ and centrifuged at $3,000 \mathrm{rpm}$ and plasma obtained was freezed in a refrigerator at $-20^{\circ} \mathrm{C}$. Extreme care was taken to remove all red blood cells and platelets from the supernatant fluid before freezing.

\section{PGE assay:}

Plasma PGE was assayed by a radioimmunoassay of Inagawa. ${ }^{12)}$ As shown 
in Fig. 1, plasma sample $(1 \mathrm{ml})$ was extracted with Folch solution. Sephadex G-25 column was used to separate the non-lipid contaminants. After the evaporation of the eluted solution, the residue was dissolved in carbon tetrachloride and prostaglandins were extracted with phosphate buffer. The aqueous phase was acidified with hydrochloric acid to $\mathrm{pH} 3.0$. After the extraction of prostaglandins with ethyl acetate, the ethyl acetate layer was neutralized with ammonium hydroxide. After the evaporation of the solvent, thin layer chromatography of silica gel was used to separate three major groups of prostaglandins. After the separation, PGE was assayed using anti-PGE 1 antibody. Dextran coated charcoal in phosphate buffer was used to separate bound and free prostaglandins. The supernatant was decanted into $10 \mathrm{ml}$ of scintillation fluid and counted in a scintillation counter for $2 \mathrm{~min}$. Results are expressed in nanograms per milliliter of plasma. The recovery from the extraction and chromatographic separation with ${ }^{3} \mathrm{H}$-labeled $\mathrm{PGE}_{1}$ was about $61 \%$.

\section{Materials :}

Angiotensin II was obtained from Protein Research Foundation. Prostaglan$\operatorname{din} \mathrm{E}_{1}, \mathrm{~F}_{2 a}$, and anti $\mathrm{PGE}_{1}$ antibody were gifts from Ono Pharmaceutical Co. ${ }^{{ }^{3} \mathrm{H}-}$

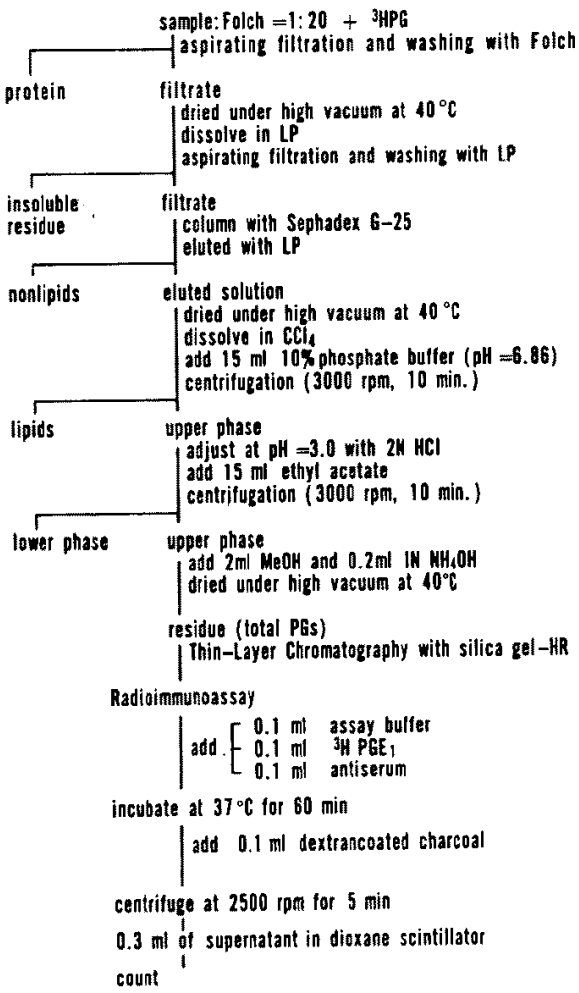

Fig. 1. Radioimmunoassay of PGF. Folch; the mixture $\mathrm{CHCl}_{3}$ : $\mathrm{CH}_{3} \mathrm{OH}=2: 1$. LP, UP; LP means lower phase that formed by the mixture $\mathrm{CHCl}_{3}: \mathrm{CH}_{3} \mathrm{OH}: \mathrm{HCl}(\mathrm{pH} \mathrm{2.0})=200: 100: 75$, and UP means upper phase. Developing solvent system; $\mathrm{CHCl}_{3}$ : EtOAc: EtOH: $\mathrm{AcOH}=200: 200: 40: 10$. 
labeled $\mathrm{PGE}_{1}$ was obtained from New England Nuclear.

All samples were assayed in duplicate. Results were expressed as mean \pm standard error. The Student $t$ test was used for statistical analysis. A probability (p) value of less than 0.05 was taken as a significant difference.

\section{Results}

The effects of indomethacin on the pulmonary arterial pressure:

Small but non significant transient increase in pulmonary arterial and aortic pressures was observed after the injection of $5 \mathrm{mg} / \mathrm{Kg}$ of indomethacin in 13 dogs. However, the increase in pressure returned toward control value 15 min after the injection (Fig. 2). The modulation by indomethacin of the effect of angiotensin II, $\mathrm{PGF}_{2 a}$, and $\mathrm{PGE}_{1}$ on pulmonary circulation was evaluated in 48 dogs. The increase in pulmonary arterial pressure by the infusion of these substances in the right ventricle was compared with and without administration of indomethacin. With indomethacin, the rise in pulmonary arterial systolic pressure by angiotensin II was augmented significantly at 10 and $15 \mathrm{~min}$ after the beginning of the infusion $(\mathrm{p}<0.02, \mathrm{p}<0.005)$, whereas that by $\mathrm{PGF}_{2 \alpha}$ was not augmented significantly. The decrease in pulmonary arterial pressure by $\mathrm{PGE}_{1}$ did not change with pretreatment of indomethacin (Fig. 3). The rise in total pulmonary resistance ( $\triangle$ TPR) and the decrease in cardiac output $(\Delta \mathrm{CO})$ by angiotensin II changed significantly at $10 \mathrm{~min}$ with pretreatment of indomethacin $(\mathrm{p}<0.05, \mathrm{p}<0.05)$. However, these changes returned to control value at $20 \mathrm{~min}$ after the infusion (Fig. 4).

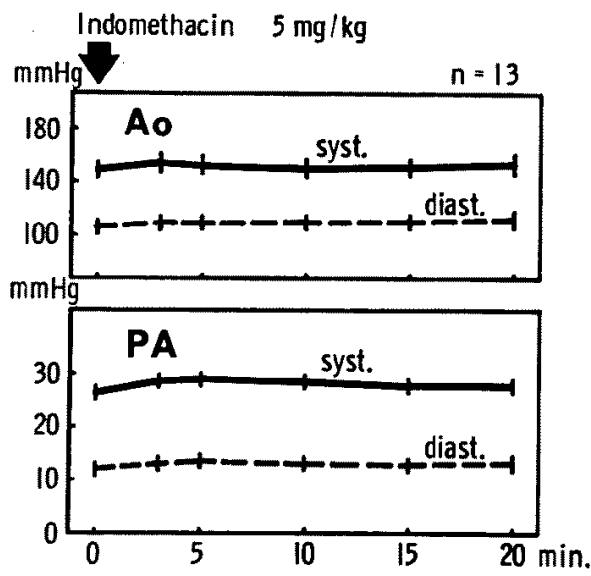

Fig. 2. Effect of indomethacin on pulmonary and systemic blood pressures. Indomethacin $5 \mathrm{mg} / \mathrm{Kg}$ was injected into the right ventricle. Ao: Aorta, PA: Pulmonary artety. 



Fig. 3. The modulation by indomethacin of the effects of angiotensin II, $\mathrm{PGF}_{2 \alpha}$ and $\mathrm{PGE}_{1}$ on pulmonary arterial systolic pressure. Indomethacin $(5 \mathrm{mg} / \mathrm{Kg}$ ) was injected into the right ventricle $20 \mathrm{~min}$ earlier. Student t test was used for statistical analysis. $\triangle \mathrm{PA}$ : Difference of pulmonary arterial blood pressure.

Tracings from the experiment were illustrated in Fig. 5. As shown in Fig. 5, the rise in pulmonary arterial pressure by angiotesin II was augmented significantly with pretreatment of indomethacin, while the aortic and right ventricular pressures and max dp/dt of RV by these substances did not change significantly with pretreatment of indomethacin (Table I).

The modulation by indomethacin of the effect of angiotensin II on the pulmonary arterial plasma PGE levels: 

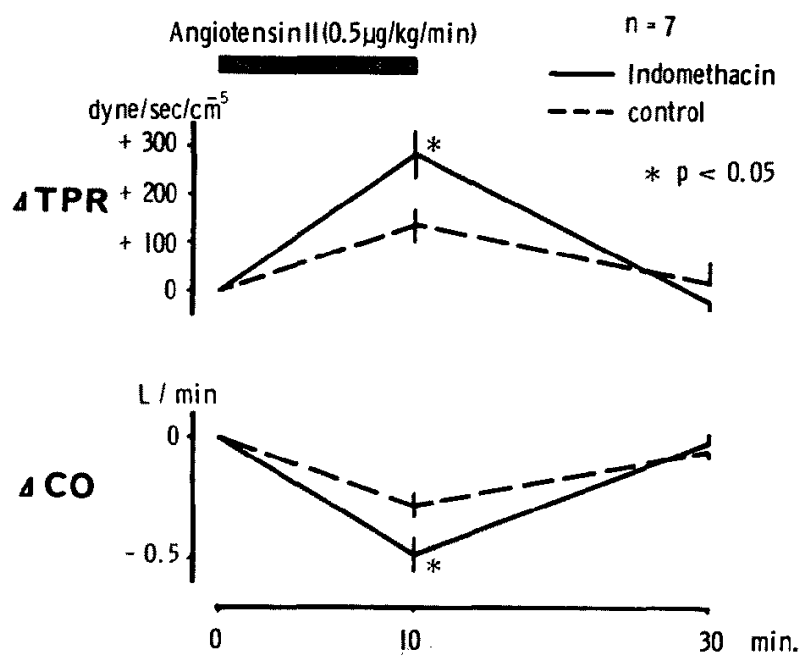

Fig. 4. Effects of angiotensin $11(0.5 \mu \mathrm{g} / \mathrm{Kg} / \mathrm{min}, 10 \mathrm{~min})$ on total pulmonary resistance and cardiac output the with and without administration of indomethacin. Student $t$ test was used for statistical analysis. TPR: Total pulmonary resistance, CO: Cardiac output.

Table I. Effects of Angiotensin II, $\mathrm{PGF}_{2 a}$, and $\mathrm{PGE}_{1}$ on Pulmonary Arterial Pulmonary Resistance, and Cardiac Output With

\begin{tabular}{|c|c|c|c|c|}
\hline & & \multicolumn{3}{|c|}{ Angiotensin II $(0.5 \mu \mathrm{g} / \mathrm{Kg} / \mathrm{min}, 10 \mathrm{~min})$} \\
\hline & & $\begin{array}{c}\text { control } \\
(n=7)\end{array}$ & $\begin{array}{l}\text { Indomethacin } \\
\qquad(\mathrm{n}=7)\end{array}$ & $\mathbf{p}$ \\
\hline $\mathrm{Pa}$ pressure(s) & $(A \mathrm{mmHg})$ & $4.1 \pm 0.6$ & $8.6 \pm 1.4$ & $<0.02$ \\
\hline Pa pressure(d) & $(\Delta \mathrm{mmHg})$ & $2.4 \pm 1.3$ & $4.6 \pm 1.7$ & n.s. \\
\hline $\mathrm{RV}$ pressure $(\mathbf{s})$ & $(\Delta \mathrm{mmHg})$ & $0.3 \pm 0.6$ & $3.1 \pm 1.7$ & n.s. \\
\hline Ao pressure(s) & $(\Delta \mathrm{mmHg})$ & $35.6 \pm 5.3$ & $42.3 \pm 5.0$ & n.s. \\
\hline Ao pressure(d) & $(\Delta \mathrm{mmHg})$ & $42.1 \pm 7.1$ & $39.0 \pm 4.5$ & n.s. \\
\hline $\max R V d p / d t$ & $(\%)$ & $110.6 \pm 9.9$ & $106.6 \pm 7.4$ & n.s. \\
\hline TPR & $\left.\mathrm{e} / \mathrm{sec} / \mathrm{cm}^{-5}\right)$ & $138 \pm 36$ & $287 \pm 55$ & $<0.05$ \\
\hline $\mathrm{CO}$ & $(\Delta \mathrm{L} / \mathrm{min})$ & $-0.28 \pm 0.05$ & $-0.49 \pm 0.07$ & $<0.05$ \\
\hline
\end{tabular}

All values were expressed as mean $\pm \mathrm{SE} . \quad \mathrm{Pa}=$ Pulmonary artery, $\mathrm{RV}=\mathrm{Right}$ ventricle, Ao= Aorta, $\mathbf{s}=$ systolic, $\mathrm{d}=$ diastolic, $\mathrm{TPR}=$ Total pulmonary resistance, $\mathrm{CO}=$ Cardiac output, $\mathrm{n}=$

Pulmonary arterial plasma PGE levels rose significantly from $0.52 \pm$ 0.10 (SE) $\mathrm{ng} / \mathrm{ml}$ to $0.85 \pm 0.07$ by the infusion of angiotensin II. This increase was not observed when $5 \mathrm{mg} / \mathrm{Kg}$ of indomethacin was given $20 \mathrm{~min}$ before the infusion of angiotensin II (Table II, Fig, 6). There was an augmentation 


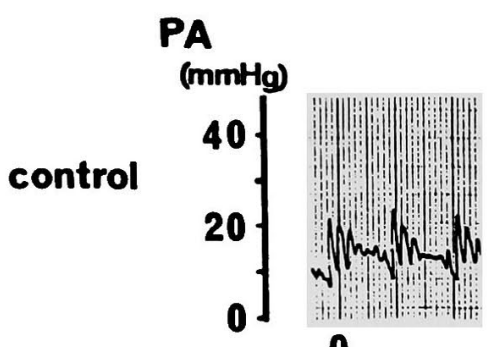

0

Angiotensin II (0.5 $\mathrm{gg} / \mathrm{kg} / \mathrm{min})$

An

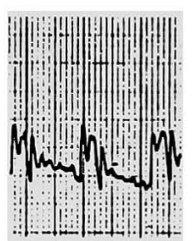

5

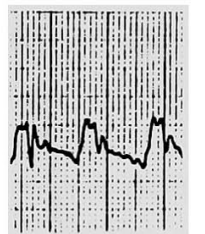

10

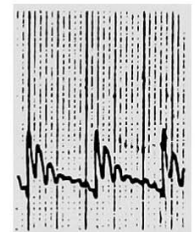

$30 \mathrm{~min}$.

Angiotensin II (")

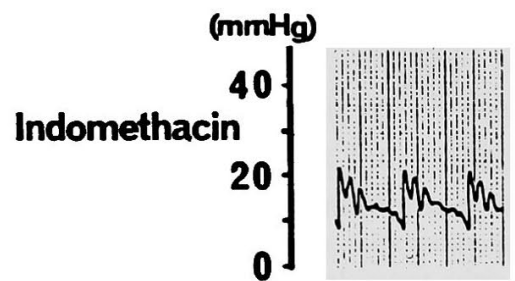

o
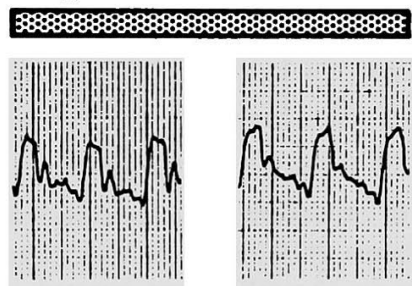

5

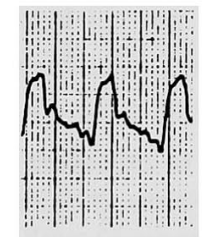

10

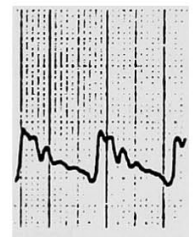

$30 \mathrm{~min}$.

Fig. 5. Effects of angiotensin II on pulmonary arterial pressure with and without the administration of indomethacin. Indomethacin $(5 \mathrm{mg} / \mathbf{K g})$ was injected into the right ventricle 20 min earlier. PA: Pulmonary artery.

Pressure, Right Ventricular Pressure, Aortic Pressure, MaxRVdp/dt, Total and Without Administration of Indomethacin

\begin{tabular}{|c|c|c|c|c|c|}
\hline \multicolumn{2}{c|}{$\mathrm{PGF}_{2 \alpha}(1.0 \mu \mathrm{g} / \mathrm{Kg} / \mathrm{min}, 10 \mathrm{~min})$} & \multicolumn{2}{|c|}{$\mathrm{PGE}_{1}(1.0 \mu \mathrm{g} / \mathrm{Kg} / \mathrm{min}, 10 \mathrm{~min})$} \\
\hline $\begin{array}{c}\text { control } \\
(\mathrm{n}=10)\end{array}$ & $\begin{array}{c}\text { Indomethacin } \\
(\mathrm{n}=7)\end{array}$ & $\mathrm{p}$ & $\begin{array}{c}\text { control } \\
(\mathrm{n}=10)\end{array}$ & $\begin{array}{c}\text { Indomethacin } \\
(\mathrm{n}=7)\end{array}$ & $\mathrm{P}$ \\
\hline $7.2 \pm 1.6$ & $10.6 \pm 2.2$ & n.s. & $-3.1 \pm 0.7$ & $-5.7 \pm 2.7$ & n.s. \\
$5.0 \pm 1.0$ & $6.4 \pm 2.0$ & n.s. & $-1.6 \pm 0.7$ & $-3.4 \pm 2.2$ & n.s. \\
$1.8 \pm 2.0$ & $2.8 \pm 1.5$ & n.s. & $-2.0 \pm 2.2$ & $1.2 \pm 2.4$ & n.s. \\
$2.0 \pm 4.3$ & $5.0 \pm 4.3$ & n.s. & $-26.1 \pm 3.9$ & $-16.0 \pm 5.2$ & n.s. \\
$0.6 \pm 3.3$ & $9.7 \pm 3.4$ & n.s. & $-22.3 \pm 4.4$ & $-15.3 \pm 4.3$ & n.s. \\
$115.1 \pm 6.4$ & $107.4 \pm 3.9$ & n.s. & $95.1 \pm 7.7$ & $113.5 \pm 14.3$ & n.s. \\
& & & & & \\
\end{tabular}

number of dogs. Statistical significace was determined by a Student $t$ test.

of the pulmonary vasoconstrictor action of angiotensin II as indomethacin blocked an increase of pulmonary arterial PGE level. 


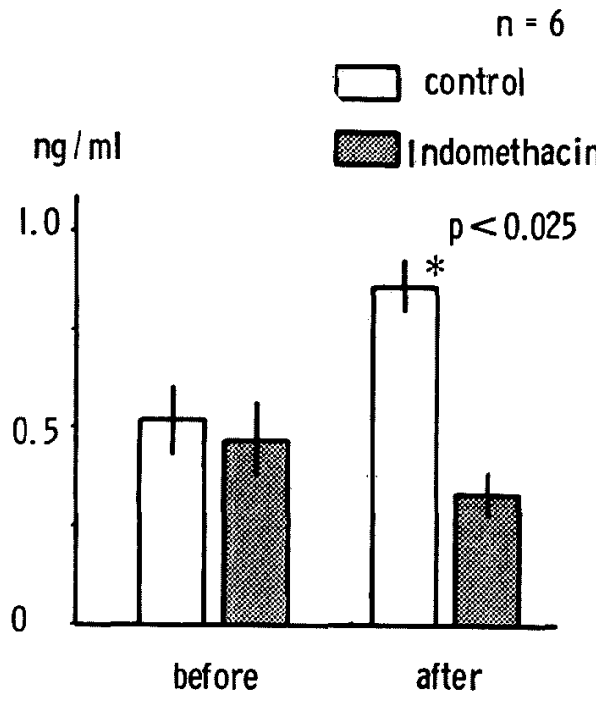

Fig. 6. Effects of angiotensin II $(0.5 \mu \mathrm{g} / \mathrm{Kg} / \mathrm{min}, 10 \mathrm{~min})$ on pulmonary arterial plasma PGE levels with and without administration of indomethacin. Indomethacin $(5 \mathrm{mg} / \mathrm{Kg})$ was injected into right ventricle $20 \mathrm{~min}$ earlier. Student $t$ test was used for statistical analysis.

Table II. Efiects of Angiotensin II and Indomethacin on Pulmonary Arterial Plasma Prostaglandin E Levels (as PGE $_{1}$ )

\begin{tabular}{|c|c|c|c|c|c|c|}
\hline & before & $\begin{array}{c}\text { Angiotensin II } \\
(0.5 \mu \mathrm{g} / \mathrm{Kg} / \mathrm{min})\end{array}$ & & before & $\begin{array}{l}\text { Indomethacin } \\
(5 \mathrm{mg} / \mathrm{Kg})\end{array}$ & $\underset{(0.5 \mu \mathrm{g} / \mathrm{Kg} / \mathrm{min})}{\text { Angiotensin II }}$ \\
\hline No. 1 & 0.37 & 0.50 & No. 7 & 0.52 & 0.24 & 0.37 \\
\hline No. 2 & 0.75 & 0.90 & No. 8 & 0.47 & 0.80 & 0.44 \\
\hline No. 3 & 0.52 & 1.00 & No. 9 & 0.50 & 0.62 & 0.23 \\
\hline No. 4 & 0.29 & 0.82 & No. 10 & 0.26 & 0.33 & 0.21 \\
\hline No. 5 & 0.34 & 0.94 & No. 11 & 0.47 & 0.44 & 0.24 \\
\hline No. 6 & 0.86 & 0.96 & No. 12 & 0.55 & 0.47 & 0.50 \\
\hline Mean & 0.52 & 0.85 & Mean & 0.46 & 0.48 & 0.33 \\
\hline$\pm \mathrm{SE}$ & 0.10 & 0.07 & $\pm \mathrm{SE}$ & 0.04 & 0.08 & 0.05 \\
\hline $\mathrm{p}$ & \multicolumn{2}{|c|}{$<0.025$} & $\mathrm{P}$ & \multicolumn{2}{|c|}{ n.s. } & \\
\hline
\end{tabular}

All values were expressed in $\mathrm{ng} / \mathrm{ml}$. Statistical significance was determined by a Student $\mathrm{t}$ test.

\section{Discussion}

It has been reported that lungs have marked biosynthetic capacity and release prostaglandins in response to a number of physiologic and pathophysiologic stimuli including hyperinflation, anaphylaxis, hypoxia, and pulmonary

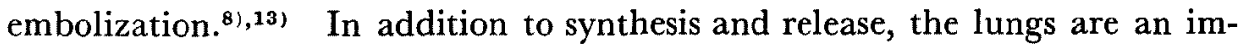
portant organ for metabolism, and approximately $90 \%$ of $\mathrm{E}$ and F-series of 
prostaglandins are metabolized during a single injection or continuous infusion, whereas A-series prostaglandins are somewhat more resistant. ${ }^{14,15}$,

Prostaglandins have been shown to have the ability to modulate the actions of the adrenergic nervous system and of pressor hormones in a number of peripheral vascular bed.,1,16),17) Prostaglandins are released by sympathetic nerve stimulation from a variety of organs. Prostaglandins Eseries, which represent the major type released by nerve stimulation, usually inhibit adrenergic transmission by depressing effects on the adrenergic transmitter at a postjunctional level, and sometimes specifically by inhibiting release of transmitter from nerve terminals. Opposite effects are usually seen with prostaglandins $\mathrm{F}$-series, which facilitate responses produced by sympathetic nerve stimulation and occasionally increase the responsiveness of effectors to norepinephrine. ${ }^{17)}$ Pressor hormone angiotensin II has been shown to stimulate the release of PGE like material into the venous effluent of the isolated, perfused rabbit kidney ${ }^{5}$ and into the renal venous blood of the intact canine kidney.6) Gimbrone and Alexander demonstrated a dose dependent increase in the production of immunoreactive PGE by endothelial cells of cultured umbilical vein when angiotensin II was added to the medium." In addition, indomethacin has been shown to enhance pressor responses to norepinephrine and angiotensin in the canine renal vascular bed, ${ }^{6)}$ and in the perfused rabbit mesenteric vascular beds. ${ }^{\text {" }}$

In the pulmonary vascular bed, Kadowitz et al reported that indomcthacin enhanced the constrictor response to angiotensin II and $\mathrm{PGF}_{2 \alpha}$, and the dilator response to $\mathrm{PGE}_{1}$ in dogs using a catheterization technique designed for pump perfusion of a lobe, which was hemodynamically separate from the main pulmonary artery, at a constant rate of flow. ${ }^{8)}$ There is no report illustrating the effects of angiotensin II and indomethacin on the pulmonary arterial blood levels of prostaglandins.

Our findings indicated that the concentration of pulmonary arterial plasma PGE rose by the infusion of angiotensin II. Furthermore, our results showed that there was an augmentation of the pulmonary vasoconstrictor actions by angiotensin II at the same time when indomethacin blocked the increase of pulmonary arterial PGE levels. On the other hand, the increase in pulmonary arterial pressure by intra-right ventricular infusion of $\mathbf{P G F}_{2 \alpha}$ was not augmented significantly and the decrease in pulmonary arterial pressure by $\mathrm{PGE}_{1}$ did not change with pretreatment of indomethacin. The explanation for differences in pulmonary vascular responses to $\mathrm{PGF}_{2 \alpha}$ and $\mathrm{PGE}_{1}$ with administration of indomethacin is not clear. Differences may be due to experimental methods, because they used a catheterization technique designed for pump perfusion of a lobe at constant rate of flow, and we used intact dogs. 
The responses of the pulmonary vessels of intact dogs to prostaglandins and angiotensin II are usually affected by the cardiac and peripheral effects of these agents. It has been known that angiotensin II exerts a positive inotropic action. ${ }^{19)}$ On the other hand, prostaglandins have been reported to exert both positive ${ }^{20), 21)}$ and negative ${ }^{16)}$ inotropic actions. The rise in pulmonary arterial pressure and total pulmonary resistance in response to angiotensin II was augmented significantly with the pretreatment of indomethacin, while the aortic and right ventricular pressures and $\max \mathrm{dp} / \mathrm{dt}$ of $\mathrm{RV}$ did not change significantly. Furthermore the decrease in cardiac output by angiotensin II was augmented significantly with the pretreatment of indomethacin. From these findings, it was suggested that the rise in pulmonary arterial pressure by angiotensin II with the pretreatment of indomethacin seemed to indicate the vasoconstriction of the pulmonary vessels.

Plasma PGE levels of pulmonary artery did not change at $20 \mathrm{~min}$ after the administration of $5 \mathrm{mg} / \mathrm{Kg}$ of indomethacin. Speckart reported that a single dose of indomethacin did not change basal unstimulated immunoreactive (IR) PGA levels, but chronic administration lowered IR-PGA levels in man. ${ }^{10)}$ Therefore chronic administration may lower basal unstimulated pulmonary arterial plasma PGE levels.

The productive site of vasodilatory prostaglandin is speculative, but the contracting vascular wall (endothelium) and kidney appear to be most likely organs. ${ }^{6,7), 9)}$ Endogenous prostaglandins are generally thought to act locally in or near the tissue in which they are formed.71,18) Therefore pulmonary arterial prostaglandins seem to be produced mainly by the pulmonary vascular wall.

Prostaglandins (especially PGE) may play an important physiologic role in homeostasis of pulmonary arterial pressure antagonizing the vasoconstriction of endogenous angiotensin II. The production of PGE may increase in response to increasing endogenous levels of angiotensin II and act as antagonist to vasoconstrictor activity of the renin-angiotensin system. Thus, our findings suggest that endogenous prostaglandins have an important role in regulation of the pulmonary circulation.

\section{Acknowledgements}

The authors are grateful to Professor Tatsuo Satake and Professor Noboru Yamazaki for their kind guidance and suggestion and Dr. Y. Wakamatsu, Dr. A. Kobayashi, Dr. M. Suzuki, Dr. M. Ban, Dr. H. Shiozu, Dr, T. Matsuno, Dr. K. Mizuno, Dr. S. Tsuchiya, and Dr. I. Enomoto for their cooperation. We thank Ono Pharmaceutical Co. for the gift of prostaglandins and prostaglandin antibody. 


\section{REFERENCES}

1. Nakano J, McGurdy JR: Hemodynamic effects of prostaglandins $\mathbf{E}_{1}, A_{2}$ and $F_{2 \alpha}$ in dogs. Proc Soc Exp Biol Med 128: 39, 1968

2. Carlson LA, Ekelund LG, Orö L: Clinical, metabolic and cardiovascular effects of different prostaglandins in man. Acta Med Scand 188: 553, 1970

3. Hyman AL: The active responses of pulmonary veins in intact dogs to prostaglandins $F_{2 \alpha}$ and $\mathrm{E}_{1}$. J Pharmacol Exptl Therap 165: 267, 1969

4. Kadowitz PJ, Joiner PD, Greenberg S, Hyman AL: Comparison of the effects of prostaglandins A, E, F and B on the canine pulmonary vascular bed. in Advances in Prostaglandin and Thromboxane Research, ed by Samuelsson B, Paoletti R, Raven Press, New York, Vol 1, 403,1976

5. Needlemen P, Kauffman AH, Douglas JR, Johnson EM, Marshall GR: Specific stimulation and inhibition of renal prostaglandin release by angiotensin analogs. Am J Physiol 224: 1415,1973

6. Aiken JW, Vane JR: Intrarenal prostaglandin release attenuates the renal vasoconstrictor activity of angiotensin. J Pharmacol Exptl Therap 184: 678, 1973

7. Gimbrone MA, Alexander RW: Angiotensin II stimulation of prostaglandin production in cultured human vascular endothelium. Science 189:219, 1975

8. Kadowitz PJ, Chapnick BM, Joiner PD, Hyman AL: Influence of inhibitors of prostaglandin synthesis on the canine pulmonary vascular bed. Am J Physiol 229: 941, 1975

9. Grylewski R, Grodzinska L, Korbut R, Ocetkiewicz A, Panczenko B: Regulatory role of prostaglandins in the vascular system. Mater Med Pol 7: 314, 1975

10. Speckart P, Grolub M, Zia P, Zipser R, Horton R: The effects of angiotensin II and indomethacin on immunoreactive prostaglandin A levels in man. Prostaglandins 11: 481, 1976

11. Negus P, Tannen RL, Dunn MJ: Indomethacin potentiates the vasoconstrictor actions of angiotensin II in normal man. Prostaglandins 12: 175, 1976

12. Inagawa $T$, Ohki $S$, Sawada $M$, Hirata F: Studies on extraction, separation and estimation of prostaglandins by radioimmunoassay. Yakugaku Zasshi 92: 1187, 1972 (in Japanese)

13. Said SI, Yoshida T, Kitamura S, Vreim C: Pulmonary alveolar hypoxia. Release of prostaglandins and other humoral mediators. Science 185: 1181, 1974

14. Piper PJ, Vane JR, Wyllie JH: Inactivation of prostaglandins by the lungs. Nature 225: $600, \quad 1970$

15. Robertson RP: Differential in vivo pulmonry degradation of Prostaglandin $E_{1}, B_{1}$, and $A_{1}$. Am J Physiol 228: 68, 1975

16. Hedquist $P$, Wennmalm $A$ : Comparison of the effects of prostaglandins $E_{1}, E_{2}$ and $F_{2 a}$ on the sympathetically stimulated rabbit heart. Acta Physiol Scand 83: 156, 1971

17. Brody MJ, Kadowitz PJ: Prostaglandins as modulators of the autonomic nervous system. Fed Proc 33: 48, 1974

18. Hinman JW: Prostaglandins. Ann Rev Biochem 41: 161, 1972

19. Freer RJ, Pappano AJ, Peach MJ, Bing KT, Mclean MJ, Vogel S, Sperelakis N: Mechanism for the positive inotropic effect of angiotensin II on isolated cardiac muscle. Circulat Res 39: 178,1976

20. Nakano J, Nccurdy JR: Cardiovascular effects prostaglandin $E_{1}$. J Pharmac Exp Ther 156: 538,1967

21. Jones RL, Kane KA, Ungar A: Cardiovascular actions of prostaglandin C in the cat and dog. Brit J Pharmacol 51: 157, 1974 